\title{
Effect of maternal cigarette smoking on newborn iron stores
}

\author{
Irina B. Pateva ${ }^{1 *}$, Elizabeth H. Kerling ${ }^{2}$, Manju Reddy ${ }^{3}$, Dan Chen ${ }^{3}$, Susan E. Carlson ${ }^{2,4}$ and Jakica Tancabelic ${ }^{5}$ \\ ${ }^{1}$ Department of Pediatrics, Pediatric Hematology/Oncology, Rainbow Babies and Children's Hospital, USA \\ ${ }^{2}$ Department of Dietetics and Nutrition, University of Kansas Medical Center Kansas City, USA \\ ${ }^{3}$ Department of Food Science and Human Nutrition, Iowa State University, USA \\ ${ }^{4}$ Department of Pediatrics, University of Kansas Medical Center Kansas City, USA \\ ${ }^{5}$ Stormont Vail Health Care, USA
}

\begin{abstract}
Background: Maternal smoking has been known to have a negative impact on the well being of the developing fetus. Prenatal smoking has been associated with premature births, low birth weight and with certain birth defects. Small research studies have also found a negative correlation between maternal smoking and neonatal body iron.

Objectives: To study and compare the relationship between maternal and infants' body iron in smokers and non-smokers in a large matched-pair cohort.

Methods: This was a prospective cohort study involving 144 mothers - 72 smokers and 72 non-smokers and their respective infants. Samples were obtained from maternal and infants' cord blood at delivery for Serum transferrin receptor (sTfR) and ferritin levels. Serum TfR and ferritin were measured by RAMCO ELISA and RIA assays. Total Body Iron (TBI) was calculated using the sTfR/ferritin ratio in a previously described formula by Cook et al.

Results: Women who smoked had lower sTfR, higher ferritin and higher body iron compared to nonsmoking women. In contrast to their respective mothers, we found a small, but statistically significant negative correlation between smoking and infants' total body iron. The number of packs per day smoked was also negatively correlated with infants' ferritin and total body iron. Lower birth weight was noted in babies of smokers compared to nonsmokers (mean /- SD=3270 +/-475 vs. 3393 $\mathrm{g}+/-475 \mathrm{~g}, \mathrm{p}=0.03)$.

Conclusion: Women who smoked during pregnancy had higher iron stores but their newborn infants had lower iron stores than those of non-smoking mothers. The more packs per day (PPD) and more days smoked during pregnancy led to lower total body iron of the babies. There may be a negative dose-dependent response between fetal smoke exposure and infant iron stores.
\end{abstract}

Abbreviations: STfR: Serum transferrin receptor, TBI: Total body iron, ID: Iron deficiency, SD: Standard deviation, PPD: Packs per day

\section{Introduction}

An adequate body iron balance is essential to the function of all mammalian cells. Iron deficiency (ID) is the most common micronutrient deficiency in the world affecting 2 billion individuals and $30-50 \%$ of pregnant women [1]. The requirement for absorbed iron is increased gradually throughout pregnancy from $1 \mathrm{mg} /$ day in the first trimester to almost $8 \mathrm{mg} /$ day in the third trimester. The absorbed iron is used to expand the woman's red cell mass, fulfill the fetus' iron requirements and compensate for blood loss at delivery. Iron deficiency anemia (IDA) in pregnancy is a significant concern due to the importance of iron for growth and development for the fetus and newborn infant [2].

Current initiatives to reduce the high prevalence of nutritional IDA have highlighted the need for reliable methods to assess iron status. Various iron status markers have been described in the past including serum ferritin, serum transferrin receptor (sTfR), hemoglobin and hepcidin, though most have limitations. Hepcidin, for example is a crucial protein in iron homeostasis [3] but reference values have not been determined in newborns. Maternal hemoglobin, while inexpensive and simple to test, is significantly affected by normal hemodilution of pregnancy making this marker a poor indicator of the pregnant woman's iron status [4,5].

Alternatively, serum ferritin indicates available iron stores in healthy individuals. The serum transferin receptors (sTfRs) are detached receptors from erythrocytes, and their increased number indicates depleted iron stores. Therefore, in our study we assessed maternal and newborn iron stores using the method described by Cook and Skikne [6,7] utilizing the ratio of ferritin to sTfR to calculate total body iron (TBI). Total body iron allows the spectrum of iron status to be compared among individuals.

The aim of this study was to evaluate the TBI in pregnant women

Correspondence to: Irina Pateva, MD, Rainbow Babies and Children's Hospital, 11100 Euclid Ave., Cleveland, OH 44106, USA, Tel: 216844 3345/913 575 9860; Fax: 216844 5431; E-mail: Irina.Pateva@Uhhospitals.org

Key words: cigarette smoking, pregnancy, anemia, serum iron, serum transferrin receptor, ferritin

Received: February 24, 2015; Accepted: April 04, 2015; Published: April 08, 2015 
and their infants. We evaluated the mothers' smoking status and education, and compared this information with their apparently healthy term newborn infants' iron status, birth weight and length.

We hypothesized that maternal smoking has a negative impact on infants' iron status.

\section{Methods}

\section{Subjects}

Study subjects were a subset of women enrolled in a randomized controlled phase III clinical trial to provide the omega-3 fatty acid, docosahexaenoic acid, during the last half of pregnancy (NCT00266825). Written informed consent was obtained from each pregnant woman that included permission to analyze maternal and cord blood nutrients. The local institutional review board approved the study.

For the present subordinate study, all subjects from the original trial who smoked and delivered a healthy, term infant were pair-matched for age, race and pregnancy history with a subject from the study who did not smoke. A smoker was defined as someone who smoked within 1 year of becoming pregnant whether or not she stopped smoking during pregnancy. Information about maternal background (age, number of previous births and years of education) was obtained at enrollment for the initial trial. The women answered questions about vitamin supplementation and cigarette smoking habits before and during pregnancy at enrollment and at 6 weeks postpartum. Answers were used to calculate pack years of smoking prior to pregnancy and the number of days and number of packs per day (PPD) smoked during pregnancy. Table 1 illustrates the demographic characteristics of the mothers. Information on the infant's birth weight, length, and head circumference was collected from the infant's medical record.

\section{Total body iron measurements}

We analyzed ferritin and sTfR concentration in maternal peripheral blood and infant cord blood at the time of delivery. The ferritin concentration was measured by RAMCO RIA assay according to the manufacturer's instructions. We used the RAMCO ELISA assay to measure sTfR. The total body iron was calculated using the formula described by Cook et al. [6]:

Body iron $(\mathrm{mg} / \mathrm{kg})=-\left[\log \left(\mathrm{sTfR}^{\star} /\right.\right.$ ferritin $\left.)-2.8229\right] / 0.1207$.

Positive body iron indicates availability of iron and negative body iron indicates tissue iron deficit.

Table 1. Maternal demographic characteristics.

\begin{tabular}{|l|c|c|}
\hline & Smokers $(\mathbf{n}=\mathbf{7 2})$ & Non-Smokers (n=72) \\
\hline Race/Ethnicity & & \\
\hline Caucasian & $39(54.2 \%)$ & $39(54.2 \%)$ \\
\hline African American & $28(38.9 \%)$ & $28(38.9 \%)$ \\
\hline Hispanic & $5(6.9 \%)$ & $5(6.9 \%)$ \\
\hline Education (years) & 12.5 & 14.2 \\
\hline Age at delivery (years) & 25.4 & 25.4 \\
\hline Gestational days smoked & & \\
\hline Average & 130 & NA \\
\hline Min & 0 & NA \\
\hline Max & 287 & NA \\
\hline Average cigarettes/day & 6.5 & NA \\
\hline
\end{tabular}

Table 2. Iron status markers of smoker and non smoker pregnant women.

\begin{tabular}{|l|l|l|l|l|}
\hline & $\begin{array}{l}\mathbf{s T f R} \\
(\mathbf{m g} / \mathbf{L})\end{array}$ & $\begin{array}{l}\text { Ferritin } \\
(\boldsymbol{\mu} / \mathbf{L})\end{array}$ & sTfR/Ferritin & $\begin{array}{l}\text { Body iron } \\
(\mathbf{m g} / \mathbf{k g})\end{array}$ \\
\hline Non-Smokers & $\mathbf{6 . 2 4}$ SD 3.67 & $\mathbf{3 0 . 3}$ SD 26.5 & $\mathbf{4 7 0}$ SD 647 & $\mathbf{3 . 8}$ SD 4.27 \\
\hline Smokers & $\mathbf{5 . 0 2}$ SD 2.64 & $\mathbf{3 6 . 2}$ SD 27.6 & $\mathbf{3 6 1}$ SD 649 & $\mathbf{4 . 9}$ SD 4.09 \\
\hline
\end{tabular}

Table 3. Correlation between amount of smoking and smokers' infants iron parameters and body measurements at delivery.

\begin{tabular}{|l|c|c|}
\hline & $\begin{array}{c}\text { PPD smoked } \\
\text { during pregnancy }\end{array}$ & $\begin{array}{c}\text { Number of days } \\
\text { smoked during pregnancy }\end{array}$ \\
\hline Cord STfR & NS & r 0.175 \\
Cord Ferritin & p -0.172 & 0.039 \\
& p 0.044 & r -0.199 \\
Total Body Iron & p -0.168 & $\mathbf{0 . 0 2 0}$ \\
\hline Birth Weight & p 0.048 & r -0.215 \\
& r -0.221 & p $\mathbf{0 . 0 1 1}$ \\
\hline Birth Length & p 0.008 & r -0.230 \\
& r -0.201 & p $\mathbf{0 . 0 0 6}$ \\
\hline
\end{tabular}

\section{Statistical analysis}

All statistical tests performed were non parametric, including Spearman's correlations and the exact $\mathrm{Chi}^{2}$ and Mann- Whitney U tests (SPSS v 17, Chicago, Ill). Tests were two tailed. Differences were considered statistically significant if $\mathrm{p}<0.05$.

\section{Results}

\section{Infant and maternal total body iron and smoking status}

Table 2 shows that women who smoked had lower sTfR, higher ferritin and higher body iron compared to nonsmoking women.

In contrast to their respective mothers, we found a small but statistically significant negative correlation between smoking and infants' total body iron. The number of packs per day (PPD) smoked was negatively correlated with the infants' ferritin and total body iron. The number of days smoked during pregnancy was also negatively correlated with the infants' ferritin and total body iron and positively correlated with infant's sTfR. These data are shown on Table 3.

\section{Infants' measurements at birth and smoking status}

Birth weight was lower in babies of smokers compared to nonsmokers (mean/- $\mathrm{SD}=3270+/-475$ vs. $3393 \mathrm{~g}+/-475 \mathrm{~g}, \mathrm{p}=0.03$ ). Mean head circumference measurements in babies of smokers were $34.1 \mathrm{~cm}(\mathrm{SD} 1.4 \mathrm{~cm})$ and in babies of non-smokers they were $33.9 \mathrm{~cm}$ $(\mathrm{SD} 1.6 \mathrm{~cm})$. This difference was not statistically significant. Mean body length measurements in infants of mothers who smoked were $49.8 \mathrm{~cm}$ $(\mathrm{SD} 2.5 \mathrm{~cm})$ and in infants of nonsmoking mothers $50.1 \mathrm{~cm}(\mathrm{SD} 2.6 \mathrm{~cm})$. This difference was also not statistically significant.

Correlation studies revealed that birth weight in infants of smokers was negatively correlated with PPD smoked and number of days smoked. Birth length in the same infants was also negatively correlated with PPD smoked and number of days smoked. Table 3 describes these data.

\section{Maternal education and smoking status}

Our results showed that maternal iron status increased significantly 
Table 4. Correlations between maternal education and iron parameters in smokers and nonsmokers.

\begin{tabular}{|c|c|c|c|c|}
\hline & \multicolumn{2}{|c|}{ Smokers } & \multicolumn{2}{|c|}{ Non-Smokers } \\
\hline & Spearman $r_{s}$ & p values & Spearman $r_{s}$ & p values \\
\hline PPD smoked during pregnancy & -0.244 & 0.003 & NA & NA \\
\hline No of days smoked during pregnancy & -0.323 & $<0.001$ & NA & NA \\
\hline Hemoglobin at enrollment g/dL & 0.214 & 0.071 & 0.315 & 0.007 \\
\hline Maternal ferritin at delivery $\mu \mathrm{g} / \mathrm{L}$ & 0.262 & 0.026 & 0.423 & $<0.001$ \\
\hline Maternal TBI at delivery $\mathrm{mg} / \mathrm{kg}$ & 0.153 & 0.199 & 0.321 & 0.006 \\
\hline Maternal sTfR/Ferritin & -.0192 & 0.021 & -0.321 & 0.006 \\
\hline
\end{tabular}

with increasing maternal education $\left[\mathrm{r}_{\mathrm{s}} 0.192, \mathrm{p}=0.021\right]$ in smokers and non smokers. Maternal education was inversely associated with smoking $\left[\mathrm{r}_{\mathrm{s}}(-) 0.244, \mathrm{P}=0.003\right]$ and the number of days smoked among smokers $\left[\mathrm{r}_{\mathrm{s}}(-) 0.323, \mathrm{p}<0.001\right]$ during pregnancy. Table 4 illustrates these findings.

\section{Discussion}

There are multiple factors that negatively influence fetal newborn iron stores. In developed countries, the main factors are poorly controlled gestational diabetes mellitus, intrauterine growth restriction (IUGR) due to maternal hypertension and maternal smoking [8]. Other factors include multiple gestation, preterm birth, and both acute and chronic fetal hemorrhage. Iron deficiency during the fetal and neonatal period can result in poor function of multiple organ systems, some of which might not recover despite subsequent correction of iron homeostasis [9].

To our knowledge this is the first report that compares total body iron of infants born to smokers to that of infants born to non-smokers. By measuring the TBI, we observed that maternal smoking led to lower neonatal body iron. We also found that both cigarettes smoked per day (PPD) and the number of days women smoked during pregnancy was associated with lower TBI in the infant at birth. Lower ferritin levels have been reported previously in infants of smokers compared to nonsmokers as evidence of lower neonatal iron status [10,11]. Some researchers have reported lower ferritin and higher sTFR levels in infants born to mothers who smoke and interpreted those as markers of increased erythropoiesis, but not necessarily lower body iron [5]. In contrast, Schiza et al. attributed the higher sTFR values and low ferritin values in their patient population of late preterm infants, to iron deficiency, rather than increased erythropoietic activity [12]. We found both lower plasma ferritin and higher sTfR, and based on the calculations for total body iron with the formula described by Cook et al. [6], these are indicative of lower neonatal iron status. We also found a positive relationship between newborn sTfR (i.e. as an indicator of iron deficiency) and the number of days smoked during pregnancy.

An alternative explanation of decreased newborn iron status is that placental iron transfer is impaired with maternal smoking. Higher TBI and ferritin and lower sTfR in women who smoke compared to those who did not, is consistent with reduced iron transport across the placenta. Although higher ferritin concentrations could result from chronic generalized inflammation due to smoking, inflammation seems a less likely explanation for higher maternal iron status. This is because we find lower sTfR with smoking. Lower sTfR is considered evidence of better cellular iron status, and sTfR is not influenced by inflammation. Thus we believe higher TBI in women who smoked likely reflects a significantly higher iron status compared to nonsmokers that is most likely due to reduced placental iron transport. Measurement of hemoglobin concentration, hematocrit levels and serum ferritin levels were used in previous research to determine iron stores in smoking mothers. Based on these parameters, researchers concluded that pregnant smokers have low iron stores, however, they did not directly compare iron status of smokers to nonsmokers [13-15] and many studies of pregnant women indicate lower iron status, especially when the indicator used to assess iron status is not corrected for the increase in maternal blood volume during pregnancy.

Maternal smoking affects placental blood flow and vascular resistance [16]. Indices of uterine vascular resistance were observed to increase with more tobacco exposure. A possible consequence is the decrease of blood nutrients and oxygen transported to the fetus leading to growth retardation and hypoxia. Also, hypoxia increases erythropoiesis in the fetus $[17,18]$, and this could be an alternative explanation for decreased iron stores in infants of women who smoked compared to those who did not as they are using all the available iron for red cell production without iron storing.

Many previous studies describe the effect of maternal smoking during pregnancy on infant weight. The majority of these studies show birth weight and length, as well as head circumference are lower in infants delivered to mothers who smoke compared to infants from mothers who do not smoke $[19,20]$. We confirmed the findings of a smaller study conducted by Machado et al. [16] that smoking during pregnancy leads to a decrease in birth weight and length, smoking also affected infant's weight and length measurements at birth in a dosedependent effect.

We found that maternal education correlated significantly with maternal body iron but did not correlate with the infant's total body iron at birth. Higher education correlated also with less smoking during pregnancy.

A limitation of the study is that we did not measure maternal iron intake and cannot say that intake was similar in smokers and nonsmokers. Another limitation is that we do not know if the fetus was exposed to second hand smoke from other persons who associated with the mother during pregnancy.

In conclusion, our study involves the largest sample to date regarding maternal smoking and total body iron status in term newborn infants. The majority of previous studies used cord hemoglobin level and ferritin level as indicators of the maternal and newborn's iron status. In our study sTfR, ferritin and their ratio were utilized to calculate TBI in pregnancy and at birth as a more accurate assessment of iron status. We found that infants born to mothers who smoke had low body iron while their mothers had higher body iron. We found 
inverse relationships between the amount of cigarette smoking and newborn total body iron and growth.

The results of our study should promote awareness among primary care physicians, obstetricians and pediatricians about the harmful effects of maternal smoking during pregnancy and particularly its negative, dose-dependent impact on infants' iron status. This information may be used as a reference when promoting smoking secession in pregnant women and will provide rationale for closer monitoring of iron status of infants of smokers. Ultimately, those measures will lead to optimization of infant's iron stores and decrease the negative impact of iron deficiency on growth, development and cognitive function during childhood.

\section{Grant support}

Children's Miracle Network for Department of Pediatrics, University of Kansas Medical Center, Kansas City, KS. Supported by a grant from the National Institutes of Health (HD047315).

\section{References}

1. World Health Organization (2008) Worldwide Prevalence of Anaemia 1993-2005 WHO Global Database on Anaemia. de Benoist B, McLean E, Egli I, Cogswell Mary. WHO press Geneva, Switzerland: 2008

2. Milman N (2006) Iron and pregnancy--a delicate balance. Ann Hematol 85: 559-565. [Crossref]

3. Chelchowska M, Lewandowski L, Ambroszkiewicz J, Swiatek E, Gajewska J, et al. (2008) The effect of tobacco smoking during pregnancy on concentration of prohepcidin and some parameters of iron metabolism in matched-maternal cord pairs. Przegl Lek 65: 474-478. [Crossref]

4. Siddappa AM, Rao R, Long JD, Widness JA, Georgieff MK (2007) The assessment of newborn iron stores at birth: a review of the literature and standards for ferritin concentrations. Neonatology 92: 73-82. [Crossref]

5. Sweet DG, Savage G, Tubman TR, Lappin TR, Halliday HL (2001) Study of maternal influences on fetal iron status at term using cord blood transferrin receptors. Arch Dis Child Fetal Neonatal Ed 84: F40-43. [Crossref]

6. Cook JD, Flowers CH, Skikne BS (2003) The quantitative assessment of body iron. Blood 101: 3359-3364. [Crossref]
7. Skikne BS (2008) Serum transferrin receptor. Am J Hematol 83: 872-875. [Crossref]

8. Rao R, Georgieff MK (2007) Iron in fetal and neonatal nutrition. Semin Fetal Neonatal Med 12: 54-63. [Crossref]

9. Georgieff MK (2008) The role of iron in neurodevelopment: fetal iron deficiency and the developing hippocampus. Biochem Soc Trans 36: 1267-1271. [Crossref]

10. Chelchowska M, Laskowska-Klita T (2002) Effect of maternal smoking on some markers of iron status in umbilical cord blood. Rocz Akad Med Bialymst 47: 235-240. [Crossref]

11. Ahlsten G, Tuvemo T, Gebre-Medhin M (1989) Selected trace elements and proteins in serum of apparently healthy newborn infants of mothers who smoked during pregnancy. Acta Paediatr Scand 78: 671-676. [Crossref]

12. Schiza V, Giapros V, Pantou K, Theocharis P, Challa A, et al. (2007) Serum transferrin receptor, ferritin, and reticulocyte maturity indices during the first year of life in 'large' preterm infants. Eur J Haematol 79: 439-446. [Crossref]

13. Ingvarsson RF, Bjarnason AO, Dagbjartsson A, Hardardottir H, Haraldsson A, et al. (2007) The effects of smoking in pregnancy on factors influencing fetal growth. Acta Paediatr 96: 383-386. [Crossref]

14. Bodnar LM, Siega-Riz AM, Arab L, Chantala K, McDonald T (2004) Predictors of pregnancy and postpartum haemoglobin concentrations in low-income women. Public Health Nutr 7: 701-711. [Crossref]

15. Hay G, Refsum H, Whitelaw A, Melbye EL, Haug E, et al. (2007) Predictors of serum ferritin and serum soluble transferrin receptor in newborns and their associations with iron status during the first $2 \mathrm{y}$ of life. Am J Clin Nutr 86: 64-73. [Crossref]

16. Machado Jde B, Plínio Filho VM, Petersen GO, Chatkin JM (2011) Quantitative effects of tobacco smoking exposure on the maternal-fetal circulation. BMC Pregnancy Childbirth 11: 24. [Crossref]

17. Bili H, Mamopoulos M, Tsantali C, Tzevelekis P, Malaka K, et al. (1996) Elevated umbilical erythropoietin levels during labor in newborns of smoking mothers. $\mathrm{Am} \mathrm{J}$ Perinatol 13: 85-87. [Crossref]

18. Varvarigou A, Beratis N, Makri M, Vagenakis AG (1994) Increased levels and positive correlation between erythropoietin and hemoglobin concentrations in newborn children of mothers who are smokers. J Pediatr 124: 480-482. [Crossref]

19. Delpisheh A, Attia E, Drammond S, Brabin BJ (2006) Adolescent smoking in pregnancy and birth outcomes. Eur J Public Health 16: 168-172. [Crossref]

20. Rahu K, Rahu M, Pullmann H, Allik J (2010) Effect of birth weight, maternal education and prenatal smoking on offspring intelligence at school age. Early Hum Dev 86: 493 497. [Crossref]

Copyright: (C2015 Pateva IB. This is an open-access article distributed under the terms of the Creative Commons Attribution License, which permits unrestricted use, distribution, and reproduction in any medium, provided the original author and source are credited. 